\title{
Open repair remains the gold standard
}

\author{
Jonathan C. Hong, MD, and Joseph S. Coselli, MD
}

Recent guidelines define an aortic dissection as chronic after 90 days from the time of the initial event. This chronic state reflects the loss of compliance over time in the septum separating the true and false lumens of the dissection. ${ }^{1}$ However, open repair of a dissection-related aneurysm of the distal aorta usually does not occur until years after the onset of dissection. The persistence of a pressurized false lumen weakens the outer aortic wall, leading to dilation and, possibly, to aneurysm (Figure 1). ${ }^{2,3}$ Aneurysms due to chronic aortic dissection are present in $15 \%$ to $40 \%$ of patients who undergo open repair of descending thoracic aortic aneurysm or thoracoabdominal aortic aneurysm (TAAA) ${ }^{4-7}$ In our series of 3309 patients who underwent TAAA repair, we found that $1020(31 \%)$ had chronic aortic dissection; this included $427(13 \%)$ survivors of DeBakey Type I and 593 (18\%) survivors of DeBakey Type III aortic dissection. ${ }^{5}$ These patients are distinctly different from those with degenerative atherosclerotic aneurysms. Patients with chronic aortic dissection are younger, have fewer comorbidities, and are more likely to have heritable thoracic aortic disease. In roughly one-third of patients who survive an acute dissection event (residual DeBakey Type I and index DeBakey Type III aortic dissection), a distal aortic aneurysm will subsequently develop. ${ }^{8}$ Predictors of aneurysm development after aortic dissection include uncontrolled hypertension, initial aortic diameter $>4.0 \mathrm{~cm}$, entry tear $>10 \mathrm{~mm}$, partial thrombosis or continued patency of the distal false lumen, or false lumen $>2.2 \mathrm{~cm}^{9-12}$

The American College of Cardiology and American Heart Association guidelines for patients with thoracic aortic disease recommend open distal aortic repair when aortic diameter exceeds $5.5 \mathrm{~cm}$ (class I recommendation; level of evidence B), with a lower diameter threshold in patients with a rapid rate of growth $(>0.5 \mathrm{~cm} / \mathrm{y})$ or heritable

\footnotetext{
From the Division of Cardiothoracic Surgery, Michael E. DeBakey Department of Surgery, Baylor College of Medicine; Department of Cardiovascular Surgery, Texas Heart Institute; and Department of Cardiovascular Surgery, CHI St Luke's-Baylor St Luke's Medical Center, Houston, Tex.

Dr Coselli's work is partly supported by the Cullen Foundation.

Received for publication Jan 4, 2021; accepted for publication Jan 5, 2021; available ahead of print Jan 26, 2021.

Address for reprints: Joseph S. Coselli, MD, Division of Cardiothoracic Surgery, Michael E. DeBakey Department of Surgery, Baylor College of Medicine, One Baylor Plaza, BCM 390, Houston, TX 77030 (E-mail: jcoselli@bcm.edu). JTCVS Techniques 2021;10:16-23

2666-2507

Copyright (C) 2021 The Authors. Published by Elsevier Inc. on behalf of The American Association for Thoracic Surgery. This is an open access article under the CC BY-NCND license (http://creativecommons.org/licenses/by-nc-nd/4.0/).

https://doi.org/10.1016/j.xjtc.2021.01.024
}

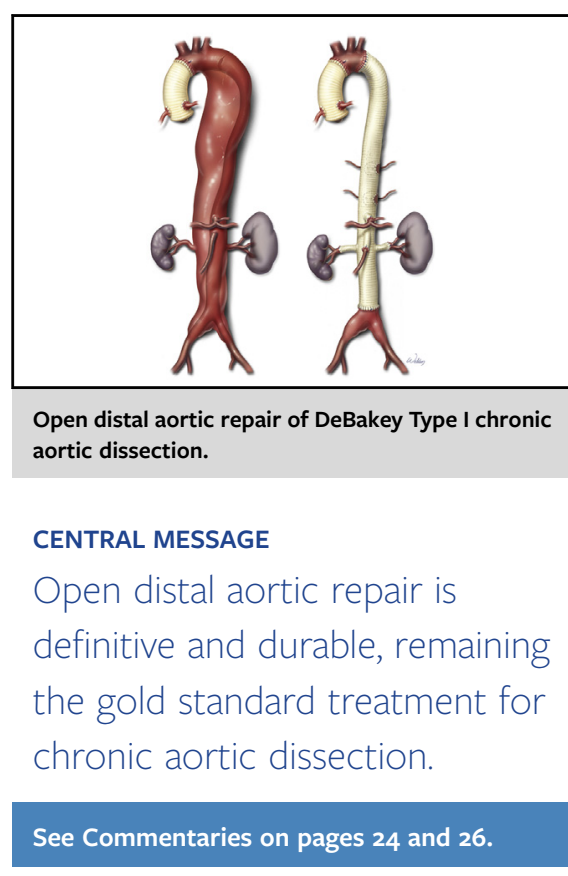

thoracic aortic disease. ${ }^{13}$ Symptomatic aneurysms can herald impending rupture and should be repaired, regardless of size. ${ }^{13}$ Other indications for open repair include compressive symptoms of adjacent structures or malperfusion syndromes. Notably, the open repair of chronic distal aortic dissection is generally performed on only the aneurysmal or symptomatic aortic segment. ${ }^{14}$ Except in the most extensive repairs, a portion of residual chronic aortic dissection often remains after repair.

Open repair of chronic aortic dissection remains the gold standard over thoracic endovascular aortic repair (TEVAR). With open repair, the thickened and stiff dissecting septum is excised, and a common lumen is created with the replacement graft. The durability of open repair has been well established. TEVAR is a burgeoning field; its application for the treatment of aortic dissection relies on covering the intimal tear and promoting aortic remodeling. However, in the chronic state, the thickened and noncompliant dissecting septum often prevents the complete elimination of false lumen blood flow, even if the entry tear is covered. The distal seal can be complicated by persistent retrograde blood flow into the false lumen, and new entry tears induced by the stent graft can develop at any point of coverage. ${ }^{15,16}$ In fact, the aortic diameter fails to regress in $70 \%$ of patients with chronic aortic dissection who undergo TEVAR. ${ }^{17,18}$ Adjunctive endovascular techniques to address the thickened, noncompliant dissecting septum include the following: obliteration of the false lumen, including 

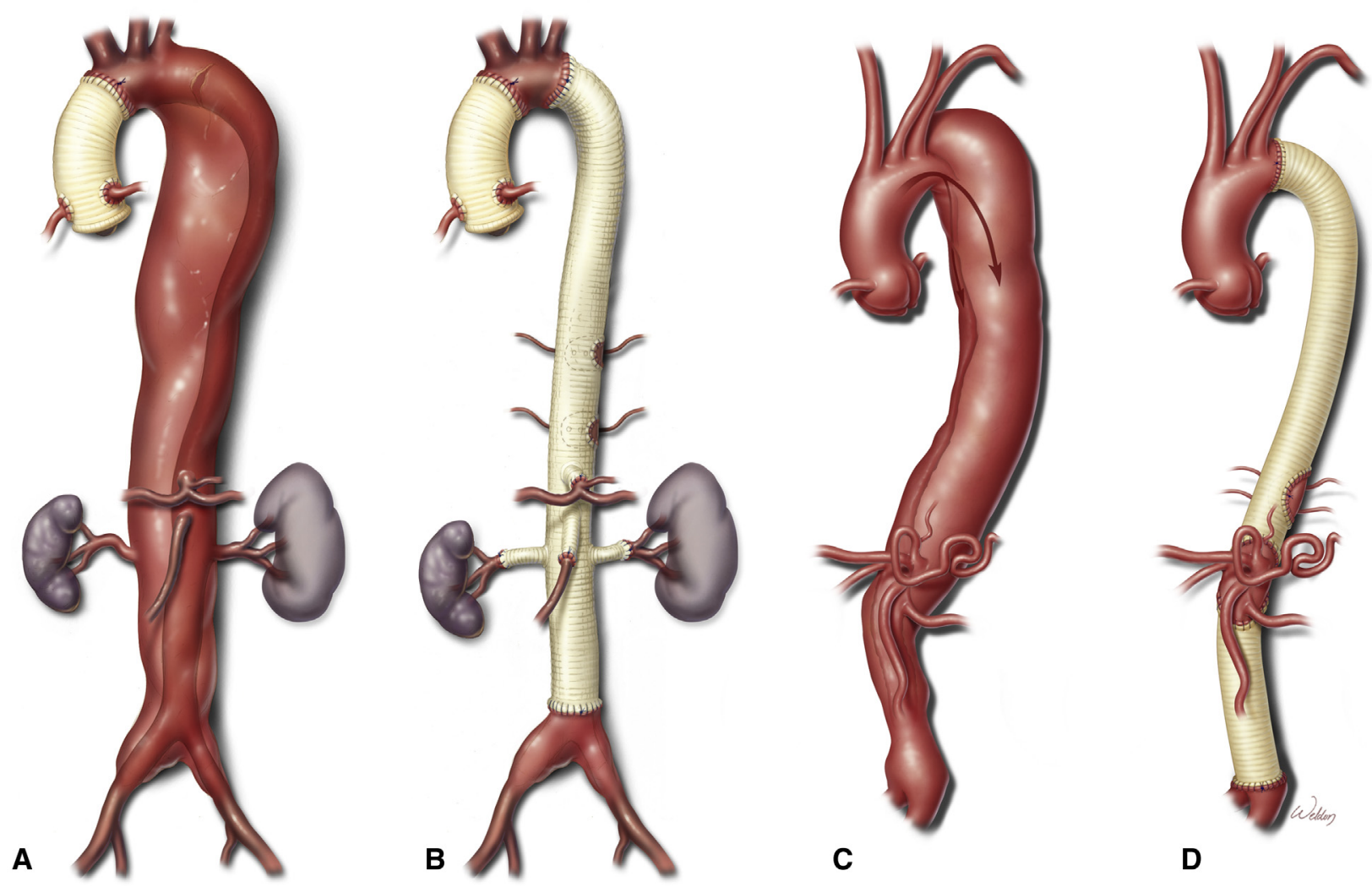

FIGURE 1. Two types of chronic aortic dissection necessitating distal aortic repair. DeBakey Type I before repair (A) and after repair (B) as well as Type III before repair (C) and after repair (D). Used with permission of Baylor College of Medicine.

embolization, by using coils or plugs; or, common aortic lumen creation by fenestration, stent-graft-assisted balloon aortic septal fracture, or provisional extension to induce complete attachment techniques. ${ }^{19-22}$

We describe our operative technique involving a 4-branched replacement graft for the open repair of extent II TAAA aneurysms due to chronic aortic dissection.

\section{PREOPERATIVE IMAGING}

A careful review of preoperative imaging is the cornerstone of TAAA repair. The surgeon must plan for potential aortic clamping and cannulation sites with respect to calcification, dissection, and mural thrombus. Although rarely used at our institution, hypothermic circulatory arrest may be necessary if there is a contained rupture or if the distal aortic arch is aneurysmal and without a suitable proximal aortic clamping site. The origins of branching vessels, including the brachiocephalic, intercostal, lumbar, visceral, renal, and iliofemoral branches, are assessed with respect to the true lumen, false lumen, or both. Dissection extending into branch vessels may require fenestration. Anatomic variation should also be examined. A left renal vein that is retroaortic may need to be divided and later reconstructed with an interposition graft. The spatial orientations of the visceral and renal arteries are assessed with consideration of an island patch or individual branching grafts. The visceral and renal arteries are often displaced because of the chronic dissection. Therefore, we typically use a prefabricated 4-branched graft for the visceral and renal anastomoses. The use of this graft also avoids the formation of a late visceral patch aneurysm by eliminating the residual aortic tissue that remains after using alternate methods of a visceral artery reattachment (ie, the visceral island patch approach may form a subsequent aneurysm). Furthermore, the use of this graft reduces the anastomotic tension of this aortic region, thereby decreasing the likelihood of late pseudoaneurysm formation, which is particularly important in patients with heritable thoracic aortic disease.

\section{PREPARATION, MONITORING, AND ADJUNCTS FOR SPINAL CORD PROTECTION}

Standard intravenous lines are inserted, including a central venous access line. A Swan-Ganz catheter and a right-sided upper extremity arterial line are obtained for hemodynamic monitoring. A double-lumen endotracheal tube is used to facilitate single-lung ventilation. The aneurysm may distort the airway such that it is difficult to navigate 
a double-lumen endotracheal tube. When anatomically necessary, our second choice is to insert a bronchial blocker. Our practice is to transfer the patient to the intensive care unit with the double-lumen endotracheal tube in place and exchange to a single-lumen endotracheal tube if we anticipate a prolonged course of mechanical ventilation. The patient's temperature passively cools to a mildly hypothermic temperature $\left(32^{\circ} \mathrm{C}-33^{\circ} \mathrm{C}\right)$. Core temperature is measured by using a temperature probe in the nasopharynx. Cerebral oximetry is monitored throughout the procedure. Although spinal cord function may be assessed during repair by using motor-evoked potential monitoring or near-infrared spectroscopy monitoring, we do not routinely use these techniques. In our previous experience with neuromonitoring, we had logistical issues with obtaining and interpreting useful information. Ultimately, we did not adopt these monitoring techniques into our practice; however, other aortic centers have demonstrated benefits with using motorevoked potentials. ${ }^{23}$

We utilize a multimodal approach to prevent spinal cord, visceral, and renal artery injury during TAAA repair. Cerebral spinal fluid (CSF) drainage is used for extent I and II repairs, for extent III repairs with the anticipation of replacing the iliac arteries, and for extent IV repairs with prior descending thoracic aneurysm or extent I repair. The CSF pressure is kept below $15 \mathrm{~mm} \mathrm{Hg}$, and CSF is drained at a maximum rate of $10 \mathrm{~mL} / \mathrm{h}$ or $25 \mathrm{~mL}$ over 4 hours. The CSF drain is secured to the patient's right back. In most cases, a left heart bypass (LHB) circuit with a cell saver for autotransfusion is used; however, a complete cardiopulmonary bypass circuit is used in cases requiring hypothermic circulatory arrest $\left(18^{\circ} \mathrm{C}-20^{\circ} \mathrm{C}\right)$. Additionally, we utilize passive mild hypothermia, sequential crossclamping, aggressive reimplantation of suitable intercostal or lumbar arteries, isothermic blood from the LHB circuit to perfuse the celiac axis and superior mesenteric artery, and cold renal solution to protect the kidneys. ${ }^{24-26}$ The mean arterial pressure is kept between 70 and $90 \mathrm{~mm} \mathrm{Hg}$, measured from the right-sided upper extremity.

\section{POSITIONING, EXPOSURE, AND LHB}

The patient is placed in the right lateral decubitus position with the upper body at $60^{\circ}$ and the hips at $30^{\circ}$ with respect to horizon by using a beanbag (Figure 2, A). The left arm is placed on an arm board at an angle above the shoulders in a freestyle swimming position. The table is flexed at the waist. This position allows for adequate exposure of the TAAA and femoral arteries. A sigmoid skin incision is made from the left scapula, along the seventh rib, across the costal margin, to the left of the umbilicus. The ribs are counted, and the sixth intercostal space is entered with the left lung collapsed. A short segment of the posterior rib may be removed to improve thoracic exposure and to prevent rib fracture from excessive retraction.
The diaphragm is divided circumferentially, leaving a 3- to 4-cm rim of tissue from the left costal margin to the aortic hiatus to preserve the neurovascular supply of the diaphragm. The peritoneum is carefully opened, ensuring that the stomach, transverse colon, and liver are not injured. Left medial visceral rotation is performed by entering the avascular plane along the line of Toldt. The stomach is palpated to ensure its adequate decompression and that the nasal gastric tube is suitably placed. The nasal gastric tube is used as a marker for the esophagus. The left ureter is identified and retracted medially with the viscera. The left renal artery is used as a landmark, and the aorta is dissected free of its fibrofatty attachments. Throughout the procedure, meticulous hemostasis is obtained during exposure to prevent blood loss and its sequela of impaired oxygen delivery and coagulopathy. The proximal aorta is circumferentially freed while protecting the left recurrent laryngeal nerve. Adhesions from a prior DeBakey Type I aortic dissection repair may increase the difficulty in preparing the proximal aorta for a crossclamp. An elephant trunk extension during the index proximal aortic repair simplifies the staged TAAA repair. ${ }^{27}$ Epiaortic ultrasound may be helpful to locate the free-floating elephant trunk graft within the proximal portion of the descending thoracic aorta.

LHB for isothermic, self-oxygenated blood perfusion is facilitated by inserting a drainage cannula in the left atrium via the left inferior pulmonary vein and a return cannula in the distal aorta. Careful review of preoperative imaging aids the selection of a cannulation site free of thick thrombus. Although the true lumen is ideally cannulated, multiple entry tears are common in the dissecting septum, which typically ensures comprehensive perfusion even if the false lumen is cannulated. Epiaortic ultrasound may also aid the identification of a suitable distal aortic cannulation site. Heparin is administered $(1.5 \mathrm{mg} / \mathrm{kg})$ to achieve an activated clotting time $>280$ seconds before the initiation of LHB at a flow of $500 \mathrm{~mL} / \mathrm{min}$, which is then increased to $3.5 \mathrm{~L} / \mathrm{min}$ once the aortic crossclamp is applied.

\section{PROXIMAL ANASTOMOSIS}

In patients with chronic aortic dissection, the distal arch tends to be dilated. A straight, padded aortic crossclamp is applied, distal to the left subclavian artery whenever possible; more commonly, it is placed proximal to the left subclavian artery. If a crossclamp is placed proximal to the left subclavian artery, then a bulldog clamp is applied across the left subclavian artery, and cerebral oximetry is monitored to ensure that blood flow to the left common carotid is not compromised. A Crafoord clamp is applied distally at the T6 to T7 vertebral level to preserve flow where the artery of Adamkiewicz commonly arises (T7-L1). The isolated aortic segment is checked to determine whether it is depressurized by gently milking the blood before distal aortic clamping. LHB flow is 

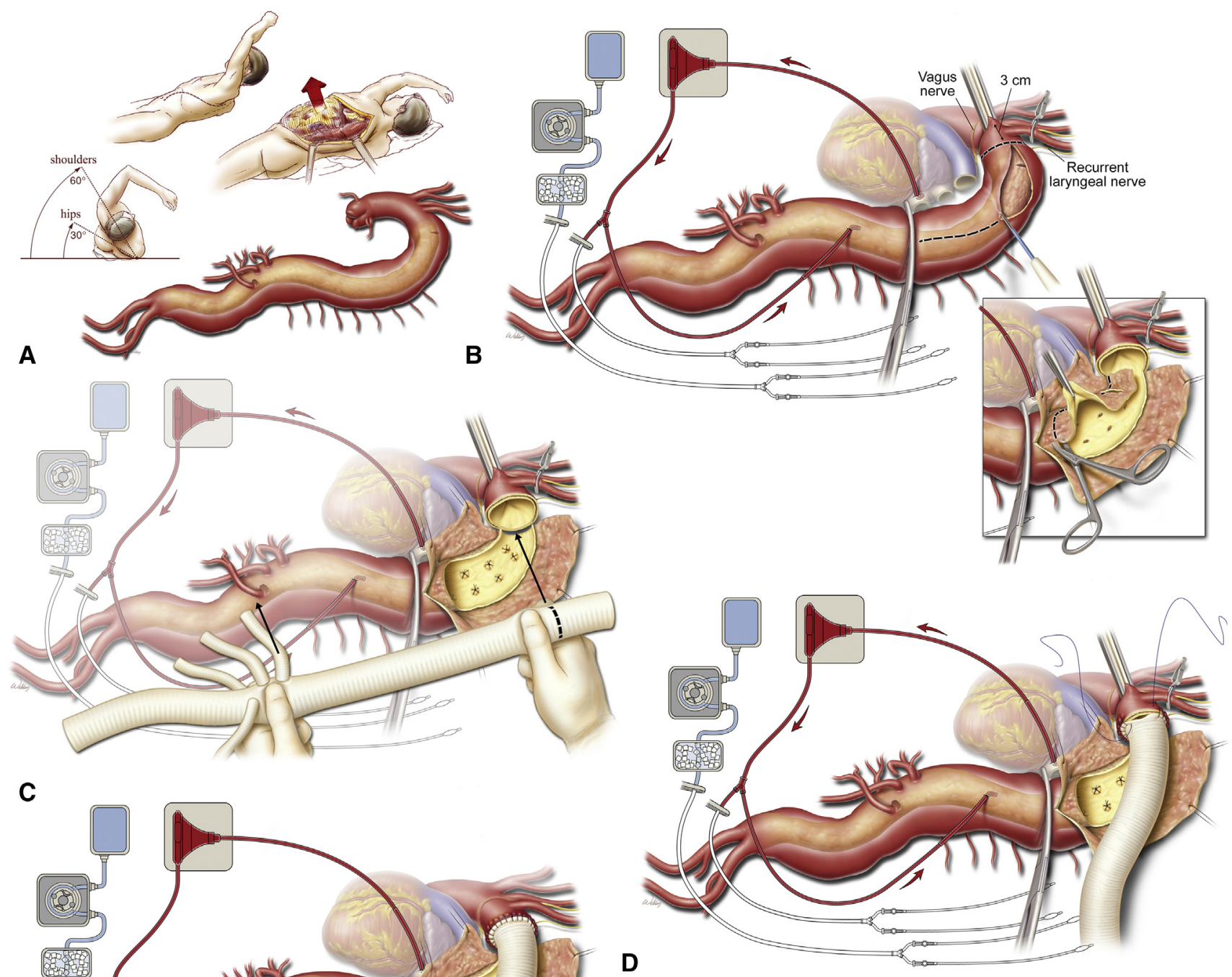

C

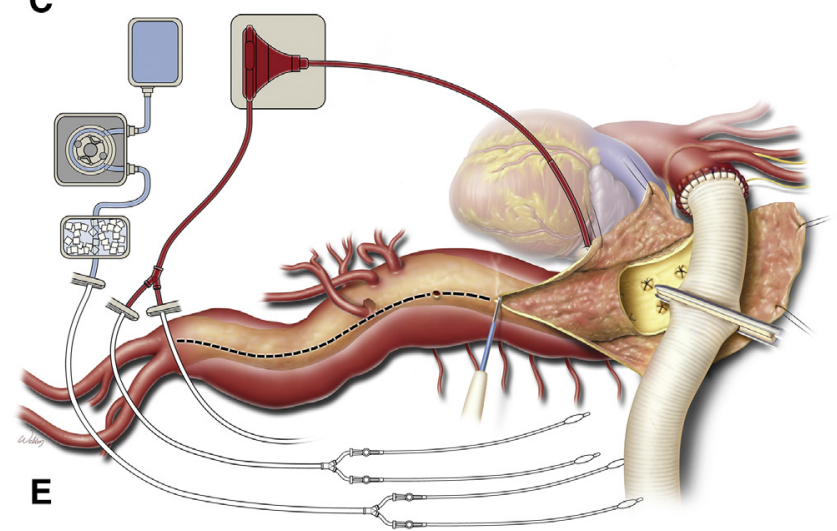

D

FIGURE 2. Repair of chronic aortic dissection in a patient with a Crawford extent II thoracoabdominal aortic aneurysm. A, Positioning of the patient and incision for thoracoabdominal extent II repair. B, Preparation of the proximal aorta, including the initiation of left heart bypass. The dissecting septum is excised (inset). C, Sizing of a branched aortic graft with respect to the visceral and renal branches. D, Construction of the proximal anastomosis. Left heart bypass is used. E, Exposure of the distal length of the aorta. F, Visceral perfusion and patch anastomosis of pairs of intercostal arteries. G, Expedited construction of the distal anastomosis when a branched graft is used. $\mathrm{H}$, Construction of right renal anastomosis. Construction of the superior mesenteric artery anastomosis, celiac axis, and left renal artery (inset). I, The completed extent II thoracoabdominal aortic repair. All figures used with permission of Baylor College of Medicine.

increased to $3.5 \mathrm{~L} / \mathrm{min}$, and a mean arterial pressure between 70 and $90 \mathrm{~mm} \mathrm{Hg}$ is maintained from the right upper extremity arterial line. The aorta is opened longitudinally, and the aortic edges are retracted with stay sutures. The chronic dissection membrane is excised, effectively creating a single lumen. Briskly back-bleeding intercostal arteries are ligated with figure-of- 8 sutures to improve visualization, minimize hemorrhage, and prevent shunting of blood from the spinal cord. In instances of hypothermic circulatory arrest, fenestration should be carried out proximally under visualization. We are careful to not aggressively excise aortic tissue, given that a transmural cut 


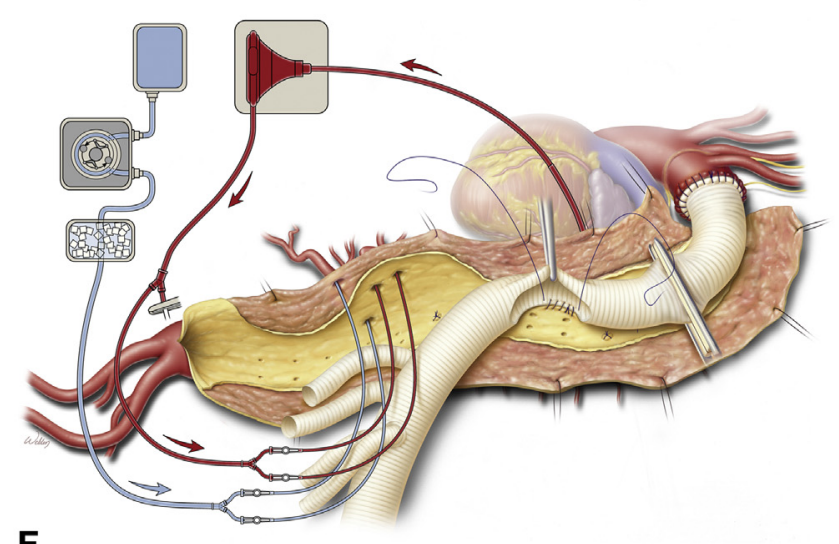

$\mathbf{F}$

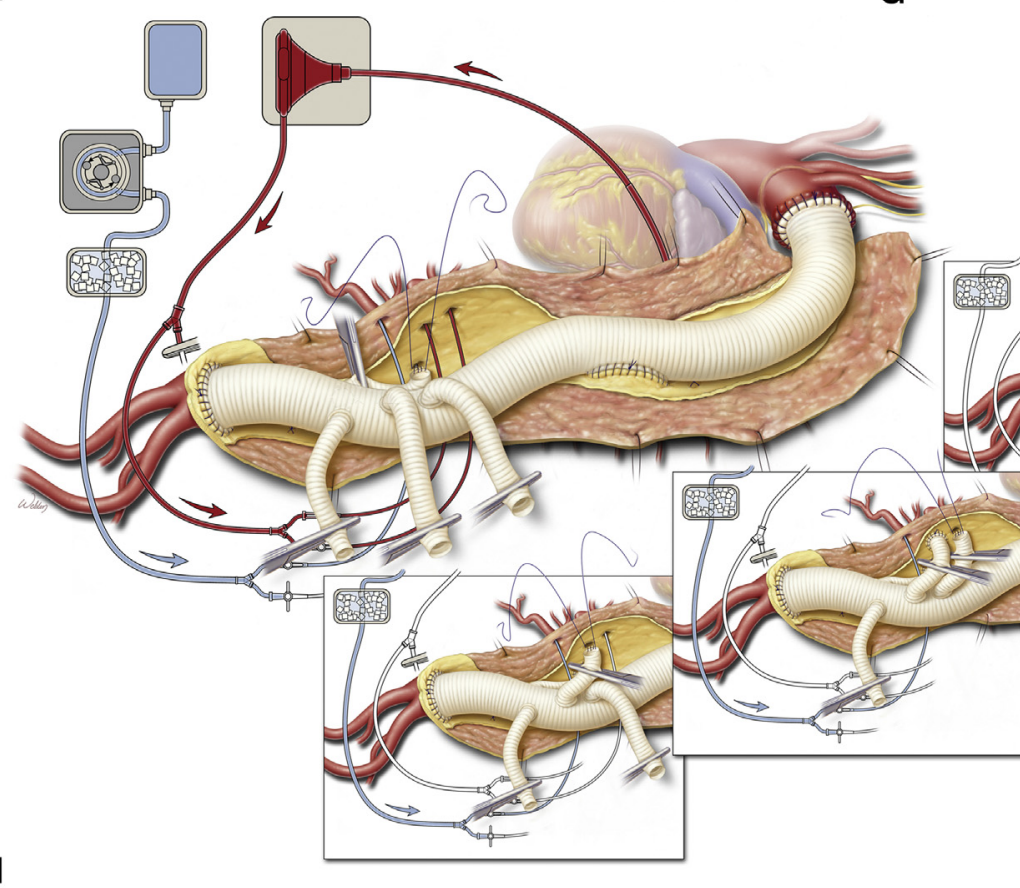

FIGURE 2. (Continued).

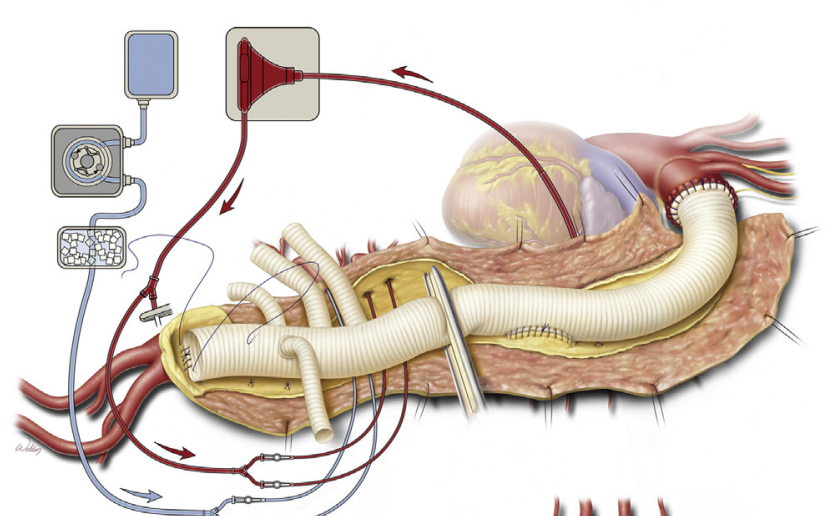

G

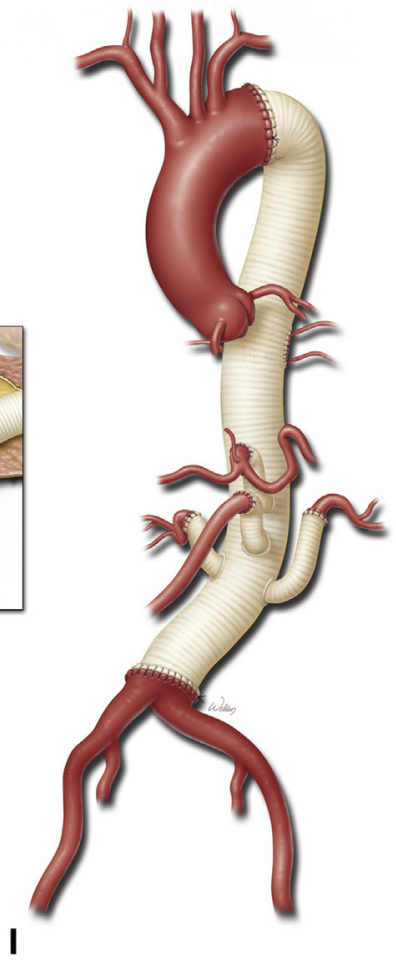

would be extremely difficult to repair in the proximal aortic arch. The aorta is trimmed for the proximal anastomosis, leaving a rim of approximately $3 \mathrm{~cm}$ (Figure 2, $B$ ). The backwall of the aorta is dissected off the esophagus to avoid including esophageal tissue in the anastomosis, which may lead to an aortoesophageal fistula. The distance from the proximal anastomosis to the visceral branches is measured by gently stretching the graft and trimming it to an approximate length (Figure 2,C). A 3-0 polypropylene suture is used in a continuous fashion; however, a 4-0 or 5-0 suture is used in patients with heritable thoracic aortic disorders. A 24- to 28-mm Dacron (DuPont, Newark, Del) graft impregnated with gelatin is typically used, which is then soaked in rifampin tableside. The anastomosis is started at the posterolateral corner and is continued medially while ensuring all layers of the aorta are included (Figure 2,D). After completion of the primary suture line, the graft is gently retracted and carefully examined for gaps, overlapping sutures, or tears in the aorta. Pledgeted mattress sutures are liberally applied to ensure a secure anastomosis, given that mean arterial pressure targets are higher during the postoperative period. The proximal crossclamp is then moved onto the graft. This clamp movement is particularly important when the clamp was placed proximal to the left subclavian artery because it re-establishes flow to the left subclavian and right vertebral artery.

\section{VISCERAL AND RENAL PERFUSION}

LHB is weaned, and the distal cannula and distal crossclamp are removed. The aorta is opened longitudinally (Figure 2, E). The dissecting membrane is excised, and 


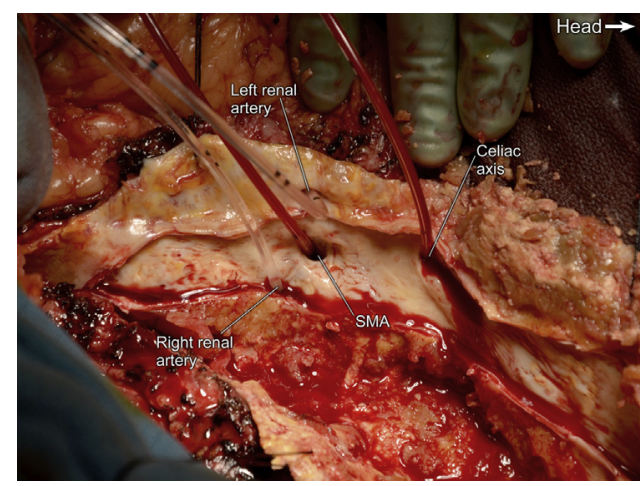

FIGURE 3. Perfusion of isothermic blood into the celiac axis and superior mesenteric artery; the renal arteries are perfused with a cold $\left(4^{\circ} \mathrm{C}\right)$ solution. $S M A$, Superior mesenteric artery. Used with permision of Baylor College of Medicine.

thrombus is removed, allowing exposure of the intercostal, visceral, and lumbar branches. Briskly back-bleeding intercostal or lumbar arteries are oversewn. Selective visceral perfusion is performed with isothermic, self-oxygenated blood through balloon-tipped catheters into the celiac axis and superior mesenteric artery at a flow of $600 \mathrm{~mL} / \mathrm{min}$ via a Y-branch off the LHB (Figure 3). The renal arteries are protected with cold $\left(4^{\circ} \mathrm{C}\right)$ perfusate $(300 \mathrm{~mL}$ every 6-12 minutes) via balloon-tipped catheters on a standalone cooling circuit while the nasopharyngeal temperature is monitored (Figure 3) not to drop below $32^{\circ} \mathrm{C}$ to prevent hypothermia-induced arrythmias. We adjust the volume and timing of the renal perfusate on the basis of the patient's temperature. An alternate perfusion strategy involves rerouting the LHB circuit with additional balloon-tipped catheters to provide isothermic, self-oxygenated blood to all 4 branching arteries.

\section{REIMPLANTATION OF INTERCOSTAL OR LUMBAR ARTERIES}

We identify 2 or 3 pairs of arteries between T7 and L2 that are large and have minimal or no back-bleeding to be utilized for reimplantation with an island patch or, less commonly, an 8-mm interposition Dacron graft (Figure 2, $F$ ). We typically reimplant using an island patch as a sideto-side anastomosis with 3-0 polypropylene suture. Occasionally, if the pairs of intercostal or lumbar arteries are spaced far apart, 2 island patches are used. To reduce the risk of subsequent pseudoaneurysm formation, we minimize the inclusion of native aorta in the patch. Pledgeted mattress sutures are used for reinforcement if the aortic tissue is fragile. The proximal crossclamp is then moved distally to the island patch to perfuse the spinal cord through the intercostal or lumbar arterial patch.

\section{DISTAL ANASTOMOSIS}

When a 4-branched replacement graft is used, the distal anastomosis is performed before reattachment of the visceral and renal arteries; this facilitates continued visceral and renal perfusion. The distal aortic anastomosis is usually sewn to the aortic bifurcation but can be constructed to the iliac or femoral arteries, as well (Figure 2, $G$ ). If the chronic dissection extends distally, the septum is fenestrated. The aortic graft is trimmed to the suitable length to prevent kinking or tension, and 3-0 polypropylene suture is used in a continuous fashion. Pledgeted mattress sutures are used to reinforce the anastomosis. The patient is placed in the Trendelenburg position, and a 19-gauge needle is used to create de-airing holes. Individual clamps are placed on each of the 4 branches. The crossclamp is slowly removed to reestablish blood flow to the lower body. Anesthesia should be prepared to resuscitate the patient to maintain mean arterial pressure upon crossclamp removal; typically, the use of bicarbonate and vasopressors is necessary.

\section{VISCERAL AND RENAL ANASTOMOSIS WITH A 4-BRANCHED GRAFT}

The ostia of the visceral and renal arteries are cut with a rim of aortic tissue to create buttons and are carefully inspected for dissection, calcium, or stenosis. If the dissection extends into the visceral arteries, fenestration is carried out on the distal aspect of the affected artery to ensure perfusion through both lumens. Endarterectomy, decalcification, or direct stenting (usually a $7-\mathrm{mm} \times 15-\mathrm{mm}$ balloonexpandable stent) may be required. The perfusion catheters are kept in place to limit ischemic time. The right renal artery is most posterior and is sewn first by using 4-0 or 5-0 polypropylene suture (Figure 2, $H$ ). The anastomosis is de-aired, and the clamp is released to re-establish perfusion. Then, the superior mesenteric artery and celiac axis anastomoses are carried out. We typically leave the superior mesenteric artery clamped during the celiac axis anastomosis to prevent back-bleeding, which affects visualization. Last, the left renal artery anastomosis is sewn. The inferior mesenteric artery is oversewn but may need to be reimplanted when there are bilateral hypogastric artery occlusions, prior colectomy, or a diseased superior mesenteric artery.

\section{HEMOSTASIS AND CLOSURE}

The 4-branched graft (Figure 2,I) is inspected for malorientation, and the distal pulse of the femoral arteries, renal arteries, celiac axis, and superior mesenteric artery are palpated. The bowel is visualized to confirm it is well perfused, and the kidneys are palpated for turgor. The spleen is inspected for any laceration or hematoma. Any splenic injury that cannot be controlled with electrocautery or packing will require a splenectomy. The patient is passively rewarmed to a target temperature of $>34.5^{\circ} \mathrm{C}$. The position of the nasal gastric tube should be confirmed. A closed-suction abdominal drain is placed in the upper left retroperitoneal space. The left hemidiaphragm is 
reapproximated with \#1 polypropylene continuous suture that is locked every 3 bites to maintain tension. Two chest tubes are placed: 1 anterosuperiorly and the other posteroinferiorly. Absorbable pericostal sutures are placed in around the ribs in a figure-of- 8 , interrupted fashion with \#2 coated braided polyester sutures. Two \#7 steel wires are also placed to secure the thoracotomy closure. The abdominal fascia is closed and tied to the diaphragmatic suture. Ventilation of the left lung is resumed, and the soft tissue is closed.

\section{POSTOPERATIVE MANAGEMENT}

Standard intensive care monitoring and volume resuscitation form the cornerstone of postoperative care in patients with TAAA. The mean arterial pressure is maintained between 80 and $100 \mathrm{~mm} \mathrm{Hg}$, and the patient's neurologic status is checked every hour. The patient's hemoglobin level is kept at or above $10 \mathrm{~g} / \mathrm{dL}$. The CSF drain can be removed between 48 and 72 hours postoperatively if there are no spinal deficits. The CSF drain is usually clamped for 8 to 12 hours before removal. The patient may be extubated the day after surgery and slowly started on a solid diet on postoperative day 4. Typically, patients are discharged 7 to 10 days after open repair. Higher mean arterial pressure goals are maintained for 4 to 6 weeks after surgery to prevent late neurologic complications.

\section{CONCLUSIONS}

In contemporary studies of distal aortic repair due to chronic dissection, the early mortality rate is $6 \%$ to $8 \%$, the stroke rate is $1 \%$ to $4 \%$, the incidence of paraplegia is $1 \%$ to $3 \%$, and the incidence of renal failure requiring dialysis is $4 \%$ to $5 \%{ }^{8,14,28-34}$ Open repair is durable. Estrera and colleagues ${ }^{30}$ reported $94 \%$ freedom from reoperation of the repaired distal aorta at 20 years, and we $\mathrm{e}^{34}$ reported $96 \%$ freedom from reoperation of the repaired distal aorta at 7 years. Additionally, Kouchoukos and colleagues ${ }^{35}$ reported excellent patency of branch grafts on follow-up angiography, with $93 \%$ freedom from occlusion at 10 years.

However, in patients with chronic aortic dissection, there is a substantial risk of late reoperation in any unrepaired distal aortic segments. $\mathrm{We}^{34}$ reported $85 \%$ freedom from progressive aortic repair at 7 years, and Estrera and colleagues $^{30}$ reported $82 \%$ freedom at 20 years. The open repair of distal aortic aneurysms due to chronic dissection remains the gold standard, demonstrating favorable outcomes and durability. However, patients with residual aortic dissection should take part in a rigorous surveillance protocol that includes imaging studies performed at regular intervals.

\section{Conflict of Interest Statement}

Dr Coselli consults for, receives royalties and a departmental educational grant from, and participates in clinical trials for Terumo Aortic; consults and participates in clinical trials for Medtronic, Inc, and W.L. Gore \& Associates; and serves as a co-investigator for CytoSorbents. Dr Hong reported no conflicts of interest.

The Journal policy requires editors and reviewers to disclose conflicts of interest and to decline handling or reviewing manuscripts for which they may have a conflict of interest. The editors and reviewers of this article have no conflicts of interest.

The authors thank Nicole Stancel, PhD, ELS(D), Department of Scientific Publications at the Texas Heart Institute, for providing editorial support, and Scott A. Weldon, MA, CMI, FAMI, for assisting with image selection and preparation. Mr Weldon's work is partly supported by the E. Stanley Crawford Endowment.

\section{References}

1. Lombardi JV, Hughes GC, Appoo JJ, Bavaria JE, Beck AW, Cambria RP, et al Society for Vascular Surgery (SVS) and Society of Thoracic Surgeons (STS) reporting standards for type B aortic dissections. J Vasc Surg. 2020;71:723-47.

2. Coselli JS, Green SY, Price MD, Hash JA, Ouyang Y, Volguina IV, et al. Results of open surgical repair in patients with Marfan syndrome and distal aortic dissection. Ann Thorac Surg. 2016;101:2193-201.

3. Schoenhoff FS, Jungi S, Czerny M, Roost E, Reineke D, Matyas G, et al. Acute aortic dissection determines the fate of initially untreated aortic segments in Marfan syndrome. Circulation. 2013;127:1569-75.

4. Conrad MF, Crawford RS, Davison JK, Cambria RP. Thoracoabdominal aneurysm repair: a 20-year perspective. Ann Thorac Surg. 2007;83:S856-61.

5. Coselli JS, LeMaire SA, Preventza O, de la Cruz KI, Cooley DA, Price MD, et al. Outcomes of 3309 thoracoabdominal aortic aneurysm repairs. J Thorac Cardiovasc Surg. 2016;151:1323-37.

6. Estrera AL, Sandhu HK, Charlton-Ouw KM, Afifi RO, Azizzadeh A, Miller CC III, et al. A quarter century of organ protection in open thoracoabdominal repair. Ann Surg. 2015;262:660-8.

7. Kulik A, Castner CF, Kouchoukos NT. Outcomes after thoracoabdominal aortic aneurysm repair with hypothermic circulatory arrest. J Thorac Cardiovasc Surg. 2011;141:953-60.

8. Alfonsi J, Murana G, Smeenk HG, Kelder H, Schepens M, Sonker U, et al. Open surgical repair of post-dissection thoraco-abdominal aortic aneurysms: early and late outcomes of a single-centre study involving over 200 patients. Eur J Cardiothorac Surg. 2018;54:382-8.

9. Bernard Y, Zimmermann H, Chocron S, Litzler JF, Kastler B, Etievent JP, et al. False lumen patency as a predictor of late outcome in aortic dissection. Am J Cardiol. 2001:87:1378-82.

10. Durham CA, Aranson NJ, Ergul EA, Wang LJ, Patel VI, Cambria RP, et al. Aneurysmal degeneration of the thoracoabdominal aorta after medical management of type B aortic dissections. J Vasc Surg. 2015;62:900-6.

11. Fattouch K, Sampognaro R, Navarra E, Caruso M, Pisano C, Coppola G, et al. Long-term results after repair of type a acute aortic dissection according to false lumen patency. Ann Thorac Surg. 2009;88:1244-50.

12. Schwartz SI, Durham C, Clouse WD, Patel VI, Lancaster RT, Cambria RP, et al. Predictors of late aortic intervention in patients with medically treated type B aortic dissection. J Vasc Surg. 2018;67:78-84.

13. Hiratzka LF, Bakris GL, Beckman JA, Bersin RM, Carr VF, Casey DE Jr, et al. 2010 ACCF/AHA/AATS/ACR/ASA/SCA/SCAI/SIR/STS/SVM Guidelines for the diagnosis and management of patients with thoracic aortic disease. A report of the American College of Cardiology Foundation/American Heart Association Task Force on Practice Guidelines, American Association for Thoracic Surgery, American College of Radiology, American Stroke Association, Society of Cardiovascular Anesthesiologists, Society for Cardiovascular Angiography and Interventions, Society of Interventional Radiology, Society of Thoracic Surgeons, and Society for Vascular Medicine. J Am Coll Cardiol. 2010;55: e27-129.

14. Preventza O, Price MD, Amarasekara HS, Tullos A, Chen P, Reidy MR, et al. Chronic Type I and Type III aortic dissections: a propensity analysis of outcomes after open distal repair. Eur J Cardiothorac Surg. 2018;54:510-6. 
15. Hughes GC. Stent graft-induced new entry tear (SINE): intentional and NOT. $J$ Thorac Cardiovasc Surg. 2019;157:101-6.

16. Andersen ND, Keenan JE, Ganapathi AM, Gaca JG, McCann RL, Hughes GC. Current management and outcome of chronic type B aortic dissection: results with open and endovascular repair since the advent of thoracic endografting. Ann Cardiothorac Surg. 2014;3:264-74.

17. Conway AM, Qato K, Mondry LR, Stoffels GJ, Giangola G, Carroccio A. Outcomes of thoracic endovascular aortic repair for chronic aortic dissections. J Vasc Surg. 2018;67:1345-52.

18. Sultan I, Siki MA, Bavaria JE, Dibble TR, Savino DC, Kilic A, et al. Predicting distal aortic remodeling after endovascular repair for chronic DeBakey III aortic dissection. Ann Thorac Surg. 2018;105:1691-6.

19. Rohlffs F, Tsilimparis N, Fiorucci B, Heidemann F, Debus ES, Kolbel T. The candy-plug technique: technical aspects and early results of a new endovascular method for false lumen occlusion in chronic aortic dissection. J Endovasc Ther. 2017;24:549-55.

20. Kölbel T, Carpenter SW, Lohrenz C, Tsilimparis N, Larena-Avellaneda A, Debus ES. Addressing persistent false lumen flow in chronic aortic dissection: the knickerbocker technique. J Endovasc Ther. 2014;21:117-22.

21. Iwakoshi S, Watkins CA, Ogawa Y, Fischbein M, Lee A, Lee JT, et al. "Cheese wire" fenestration of dissection intimal flap to facilitate thoracic endovascular aortic repair in chronic dissection. J Vasc Interv Radiol. 2020;31: $150-4$.

22. Kazimierczak A, Rynio P, Jędrzejczak T, Mokrzycki K, Samad R, Brykczyński M, et al. Expanded Petticoat technique to promote the reduction of contrasted false lumen volume in patients with chronic type B aortic dissection. J Vasc Surg. 2019;70:1782-91.

23. Jacobs MJ, Mess W, Mochtar B, Nijenhuis RJ, Statius van Eps RG, Schurink GW. The value of motor evoked potentials in reducing paraplegia during thoracoabdominal aneurysm repair. J Vasc Surg. 2006;43:239-46.

24. Coselli JS, Green SY, Price MD, Zhang Q, Preventza O, de la Cruz KI, et al. Spinal cord deficit after 1114 extent II open thoracoabdominal aortic aneurysm repairs. J Thorac Cardiovasc Surg. 2020;159:1-13.

25. Coselli JS, LeMaire SA. Left heart bypass reduces paraplegia rates after thoracoabdominal aortic aneurysm repair. Ann Thorac Surg. 1999;67:1931-4.
26. Coselli JS, LeMaire SA, Koksoy C, Schmittling ZC, Curling PE. Cerebrospinal fluid drainage reduces paraplegia after thoracoabdominal aortic aneurysm repair: results of a randomized clinical trial. J Vasc Surg. 2002;35:631-9.

27. LeMaire SA, Carter SA, Coselli JS. The elephant trunk technique for staged repair of complex aneurysms of the entire thoracic aorta. Ann Thorac Surg. 2006;81:1561-9.

28. Kouchoukos NT, Kulik A, Castner CF. Open thoracoabdominal aortic repair for chronic type B dissection. J Thorac Cardiovasc Surg. 2015;149:S125-9.

29. Conway AM, Sadek M, Lugo J, Pillai JB, Pellet Y, Panagopoulos G, et al. Outcomes of open surgical repair for chronic type B aortic dissections. J Vasc Surg. 2014;59:1217-23.

30. Estrera AL, Jan A, Sandhu H, Shalhub S, Medina-Castro M, Nguyen TC, et al. Outcomes of open repair for chronic descending thoracic aortic dissection. Ann Thorac Surg. 2015;99:786-93.

31. Pujara AC, Roselli EE, Hernandez AV, Vargas Abello LM, Burke JM Svensson LG, et al. Open repair of chronic distal aortic dissection in the endovascular era: Implications for disease management. J Thorac Cardiovasc Surg. 2012; 144:866-73.

32. Fujikawa T, Yamamoto S, Sekine Y, Oshima S, Kasai R, Mochida Y, et al. Operative results and clinical features of chronic Stanford type B aortic dissection: examination of 234 patients over 6 years. Eur J Vasc Endovasc Surg. 2015;50: 738-43.

33. Tanaka A, Sandhu HK, Afifi RO, Miller CC III, Ray A, Hassan M, et al. Outcomes of open repairs of chronic distal aortic dissection anatomically amenable to endovascular repairs. J Thorac Cardiovasc Surg. 2021;161:36-43.e6.

34. Coselli JS, Green SY, Zarda S, Nalty CC, Price MD, Hughes MS, et al. Outcomes of open distal aortic aneurysm repair in patients with chronic DeBakey type I dissection. J Thorac Cardiovasc Surg. 2014;148:2986-93.

35. Kouchoukos NT, Kulik A, Castner C. Branch graft patency after open repai of thoracoabdominal aortic aneurysms. J Thorac Cardiovasc Surg. 2017;153: S14-9.

Key Words: aortic aneurysm, aortic dissection, type B dissection, thoracoabdominal 